\title{
Effect of Intranasal Histamine on Nasal Mucosal Blood Flow and the Antidiuretic Activity of Desmopressin
}

\author{
Lawrence S. Olanoff, ${ }^{\star *}$ C. R. Titus, ${ }^{*}$ M. S. Shea, * R. E. Gibson, ${ }^{\star}$ and C. D. Brooks* \\ ${ }^{*}$ Kalamazoo Clinical Investigational Complex, Kalamazoo, Michigan 49007; and ${ }^{\ddagger}$ Drug Delivery Systems Research, \\ The Upjohn Company, Kalamazoo, Michigan 49007
}

\begin{abstract}
The effects of exogenous histamine on nasal mucosal blood flow and the systemic activity of intranasally administered desmopressin, a vasopressin analogue, were studied in normal volunteers. Ten subjects received either saline or histamine (1, 20,100 , and $500 \mu \mathrm{g}$ ) by intranasal spray. Maximal nasal mucosal blood flow response, determined by laser doppler velocimetry, demonstrated a significant $(P<0.05)$ linear relationship to histamine dose. Eight additional subjects received each of the following intranasal treatments: $20 \mu \mathrm{g}$ histamine followed by $10 \mu \mathrm{g}$ desmopressin; normal saline followed by $10 \mu \mathrm{g}$ desmopressin; $20 \mu \mathrm{g}$ histamine followed by vehicle; or normal saline and vehicle. Nasal blood flow was determined before and after each treatment. Desmopressin activity was assessed by measuring urine osmolality, flow rate, electrolyte, and creatinine concentration for $24 \mathrm{~h}$ after each treatment. The effect of histamine and desmopressin was greater than desmopressin alone, with respect to nasal blood flow response (103 \pm 24 vs. $4 \pm 17 \%$, mean \pm SEM, $P<0.02$ ), initial urine osmolality $(520 \pm 123$ vs. $333 \pm 75$ mosM, $P<0.03$ ), urine electrolyte (potassium, $45 \pm 11$ vs. $28 \pm 7$ meq/liter; sodium, $68 \pm 21$ vs. $36 \pm 8$ meq/liter, $P<0.03$ ) and creatinine concentrations (95 \pm 23 vs. $60 \pm 13 \mathrm{mg} / \mathrm{dl}, P<0.03$ ), and the duration of decrease in urine flow rate compared with saline and vehicle. These results suggest that the systemic activity of intranasal desmopressin is enhanced by increasing local nasal blood flow and are consistent with increased transnasal absorption of the peptide.
\end{abstract}

\section{Introduction}

Nasal mucosal blood flow is regulated by complex neurophysiological mechanisms, and is responsive to numerous physiological (1), pharmacological (2-5), and environmental stimuli (6). Previous reports $(2-5,7,8)$ have described the effects of various pharmacologic agents on nasal blood flow; however, there is no information available regarding the effect of nasal blood flow on the transport of drugs administered topically to the nasal mucosa in the form of sprays or aerosols. Low molecular weight, lipophilic drugs, such as propranolol (9) and progesterone (10), demonstrate high nasal mucosal permeability that results in $100 \%$ absorption, which is presumably unin-

Address reprint requests to Dr. Olanoff, Director, Drug Metabolism Research, The Upjohn Co., Kalamazoo, MI 49007. 1987.

Received for publication 3 July 1986 and in revised form 30 March

J. Clin. Invest.

(c) The American Society for Clinical Investigation, Inc.

0021-9738/87/09/0890/06 $\$ 2.00$

Volume 80, September 1987, 890-895 fluenced by nasal blood flow. For higher molecular weight, peptidic drugs, where maximal absorption is generally less than $10 \%$ (11), nasal blood flow may be a limiting factor. A potential means of enhancing nasal peptide absorption would be the administration of substances capable of increasing nasal blood flow. In theory, by increasing nasal blood flow, concentrations of drug on the basal side of the nasal mucosal membrane would remain low, increasing the effective concentration gradient, thereby augmenting peptide membrane permeation by passive diffusion.

The current study was designed to measure the nasal blood flow response of normal subjects to varying doses of exogenous histamine, a vasodilator, and to test the hypothesis that the systemic activity of an intranasally delivered peptide drug, desmopressin, would be enhanced by increasing nasal mucosal blood flow. Desmopressin acetate [1-(3-mercaptopropionic acid)-8-D-arginine vasopressin, monoacetate salt], a vasopressin analogue administered intranasally for the treatment of neurogenic diabetes insipidus (12), has an estimated intranasal bioavailability of 4-5\% (13). In these experiments nasal blood flow was measured by laser doppler velocimetry and desmopressin activity was assessed by determining the effect of the drug on urine volume flow, osmolality, and electrolyte and creatinine concentrations in water-loaded normal volunteers.

\section{Methods}

Subjects and study design. A total of 18 non-smoking normal volunteers participated in two separate experiments. They were evaluated by medical history, physical and laboratory examinations, and gave their informed consent. Specifically, subjects were excluded from study if they had a history of any allergic reactions, asthma, chronic sinusitis or rhinitis, or physical or laboratory (eosinophilia on peripheral blood smear) evidence of existing allergies, upper airway disease, or other inflammation of nasal mucosal membranes. Allergy skin tests were not performed and nasal eosinophilia was not excluded. All subjects tested were required to have anatomically acceptable nasal passages for testing and subjects with deviated or perforated septums or nasal polyps were excluded. Normal renal function was assessed by the determination of serum creatinine and blood urea nitrogen, standard urinalysis and microscopic examination on screening visits, and the determination of creatinine clearance for the 12-h period before the first day of dosing. The subjects took no medications other than study drugs from $15 \mathrm{~d}$ before the first dosing through the completion of the study.

The first experiment measured nasal blood flow response to graded doses of exogenous histamine. 10 volunteers were studied (nine males, one female), 20-44 years old (mean, $28 \mathrm{yr}$ ), weighing 53.8-90.5 kg (mean, $72.2 \mathrm{~kg}$ ). Each subject received five different, randomly assigned, double-blinded treatments (normal saline, 1, 20, 100, and 500 $\mu \mathrm{g}$ histamine), one treatment each day. After resting in a supine position for $\mathbf{3 0}$ min to allow for ambient temperature and activity equilibrations, each subject underwent a 5-min baseline determination of nasal blood flow. The subject then received one of the four histamine doses or vehicle. Each treatment was administered to a single nostril and the same nostril was used throughout the experiment. Dosing time was $20 \mathrm{~s}$ or less. Nasal blood flow was remeasured immediately after 
dosing was complete for a total of $10 \mathrm{~min}$. The subject remained supine during the dosing and throughout the 10-min post-dosing measurement sequence. Percent change in nasal blood flow from baseline was calculated as the difference between the maximum sustained postdose and predose readings, divided by the predose reading. A maximum sustained reading was defined as the highest postdose value of nasal blood flow, which was constant for $15 \mathrm{~s}$ or greater in duration. Transient variations or fluctuations due to swallowing or movement by the patients were duly marked as artifacts on the recording and disregarded. The same procedure was repeated on each of the five dosing days.

The second experiment was designed to measure the effect of intranasal histamine on the nasal absorption of desmopressin. Eight different healthy, male volunteers were studied, 18-38 yr old (mean, $25.1 \mathrm{yr}$ ), $60.9-97.5 \mathrm{~kg}$ in weight (mean, $88.2 \mathrm{~kg}$ ). The eight volunteers entered into a randomized four-way crossover, double-blinded study design. The four treatments were: (I) normal saline followed by desmopressin vehicle $(5.0 \mathrm{mg} / \mathrm{ml}$ chlorobutanol in normal saline adjusted to $\mathrm{pH} 4.0$ with $\mathrm{HCl}$ acid); (II) active histamine ( $20 \mu \mathrm{g}$ ) followed by desmopressin vehicle; (III) normal saline followed by active desmopressin $(10 \mu \mathrm{g})$; and (IV) active histamine $(20 \mu \mathrm{g})$ followed by active desmopressin $(10 \mu \mathrm{g})$.

Subjects fasted $10 \mathrm{~h}$ before, and $4 \mathrm{~h}$ after dosing for each of the four treatment regimens. They received isocaloric, caffeine-free meals consisting of $15 \%$ protein, $50 \%$ carbohydrates, and $35 \%$ fat, with adjusted sodium and potassium intakes of 60 and $40 \mathrm{meq} / 1,000 \mathrm{cal}$, respectively. Distilled water, $15.2 \mathrm{ml} / \mathrm{kg}$ body weight, for oral water loading was given $1 \mathrm{~h}$ before dosing to suppress endogenous antidiuretic hormone secretion. The subjects drank additional quantities of distilled water every $2 \mathrm{~h}$ after dosing for the first $12 \mathrm{~h}$, equal to their preceding 2-h urinary output. Urinary output was recorded every $2 \mathrm{~h}$ for the first $12 \mathrm{~h}$ followed by a 12-h collection. Nasal mucosal blood flow was measured by laser doppler velocimetry for 2 min before dosing (baseline) and immediately after dosing for $10 \mathrm{~min}$. The 2 -min determination of baseline flow was adequate, as minimal fluctuations occurred after stable probe placement was established and these fluctuations were identical to that observed in the 5-min baseline measurements performed in earlier histamine dose-response experiments. As in the first experiment, treatment phases were separated by $24 \mathrm{~h}$ and aerosols were applied to the same nostril at the same time on each experimental day.

Study medications. Histamine solutions were prepared from a commercial preparation of $1.0 \mathrm{mg}$ histamine base $/ \mathrm{ml}$, without preservative (Histamine phosphate, Sterile Ampoule No. 269; Eli Lilly \& Co., Indianapolis, IN). Desmopressin was utilized as commercially available DDAVP (USV Laboratories, Tarrytown, NY). The desmopressin vehicle contained chlorobutanol $(5.0 \mathrm{mg} / \mathrm{ml})$, sodium chloride $(9 \mathrm{mg} / \mathrm{ml})$, and hydrocloric acid (pH adjusted to 4.0$)$ in identical amounts as the commercial desmopressin preparation. Study drugs were administered as $0.1-\mathrm{ml}$ solutions by a hand-held nebulizer. In the second experiment, the histamine, or normal saline, was administered first, and was followed $30 \mathrm{~s}$ later by desmopressin, or vehicle. The nebulizer, powered by a Dyna-Vac (model 3; Cole-Parmer Instrument Co., Chicago, IL) compressor pump, emptied $100 \%$ of the volume, as measured by weighing the system before and after use. Sprayer volumes were measured by the use of calibrated syringes accurate to 0.005 $\mathrm{ml}$. The nebulizer delivered an aerosol mist with a particle size of $2.1 \pm 2.5 \mu \mathrm{M}$ (mean $\pm \mathrm{SD}$ ), with $90.6 \pm 1.3 \%$ of the delivered particles measuring $<7.5 \mu \mathrm{m}$ in diameter as determined by five trial runs. Particle size was quantitated by the use of an aerosol particle monitor which sized and counted the particles by detecting their light-scattering profile on a photomultiplier (14). During the 10-s spraying into the naris, the subject held his breath to minimize drug deposition beyond the nasal cavity.

Analytical measurements. Urine total volumes were recorded for each of the collection periods and an aliquot of each specimen was analyzed for osmolality, sodium, potassium, and creatinine concentration. Sodium and potassium concentrations were measured by an automated electrolyte analyzer (NOVA Biomedical, Newton, MA) and creatinine concentration was measured by an Autoanalyzer I instrument (Technicon, Inc., Tarrytown, NY). Urine osmolality of each sample was determined by a freezing point depression osmometer (Advanced Instruments Inc., Needham Heights, MA).

Nasal mucosal blood flow. Nasal mucosal blood flow was measured by laser doppler velocimetry using a model LD 5000 capillary perfusion monitor (Med Pacific Corp., Seattle, WA). The principles of laser doppler flow velocimetry and its use in the measurement of microcirculatory blood flow have been described in detail by Stern et al. (15) and Bonner et al. (16). The application of this technique to the measurement of nasal mucosal blood flow has been previously described by Druce et al. (17). The instrument used a low power helium neon laser to generate visible red light at a frequency of $632.8 \mathrm{~nm}$. Power was activated to the laser source for 15-30 min before the initial measurement. The monochromatic light was transmitted from the laser source through an optical fiber of $<1.0 \mathrm{~mm}$ in diameter contained in a blunt probe ( $2.0 \mathrm{~mm}$ diameter at the mucosal contacting tip). Under these conditions, light penetrated the mucosa surface to an estimated depth of $<1.0 \mathrm{~mm}$ over an approximate area of $1.0 \mathrm{~mm}^{2}$. A change in the frequency spectrum of the backscattered light was produced by the moving red blood cells in the mucosal capillaries referred to as the Doppler Shift. A parallel receiving optical fiber enclosed in the probe picked up a portion of both the frequency shifted and nonshifted backscattered light components and transmitted the light photons to a photodetector where they were mixed to produce an electrical signal. This signal was processed by analog circuitry and converted to a voltage measurement by an algorithm used to calculate the root-meansquare bandwidth of the power spectrum of the shifted frequencies. The flow reading derived was related to the product of the root-meansquare velocity of the red blood cells and the number density and mean volume of the moving cells, and was linearly proportional to blood flow in the microcirculation of the selected tissue section. To ensure a linear response, the direct current signal amplitude or mean backscattered light level over the tissue section was maintained between 900 and $1,500 \mathrm{mV}$ during the entire experiment. The subjects held their heads still during the recording procedure and the flow probe was positioned in gentle contact over the mucosal surface of the inferior aspect of the anterior nasal septum. In the first experiment, the subjects were supine and the probe was positioned by the use of a retractor attached to an earphone headset. In the second experiment, the subjects sat, placing their heads on a chin rest secured on a tripod apparatus, with the probe positioned on an adjustable clamp attached to the tripod base. The degree of probe contact with the mucosal tissue was initially adjusted until an optimal mid-range direct current signal was obtained (amplitude $1,200 \pm 100 \mathrm{mV}$ ) to provide uniform signal intensity and prevent excess pressure by the probe against the tissue.

Statistical analysis. Significance of the data was evaluated by analysis of variance with appropriate contrasts, and least-square difference techniques (18). Ranked observations were analyzed for the nasal blood flow measurements by analysis of variance in the second experiment (18). A probability value of $<0.05$ was judged to be statistically significant. Results are expressed as mean \pm standard error of the mean values.

\section{Results}

Fig. 1 shows maximal nasal blood flow response (percent change from baseline) to the graded histamine doses in the first experiment. Intranasal histamine produced an increase in nasal blood flow response that was linearly related to histamine dose $(P<0.05)$. Nasal blood flow readings generally peaked within 4-5 min after histamine dosing and returned to baseline by the end of the 10 -min recording period. The percent change in nasal blood flow after $500 \mu \mathrm{g}$ histamine $(81 \pm 26 \%)$ was significantly greater than after normal saline 


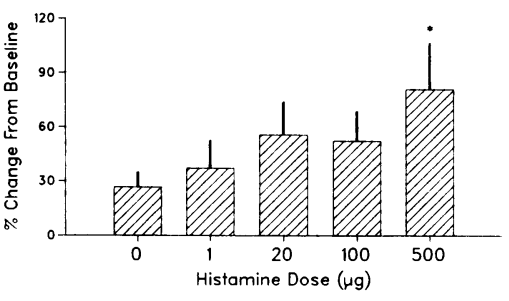
readings, divided by the predose reading, by laser doppler velocimetry techniques, $n=10$. $*$ Greater than saline, $P<0.04$; values expressed as mean \pm SEM.

(27 $\pm 8 \%, P<0.04)$. Subjective local responses to the histamine administration included nasal congestion in three subjects, and a sensation of nasal burning in one subject, all at the $500-\mu \mathrm{g}$ dose. There were no complaints of sneezing, itching, or rhinorrhea. A total of four subjects reported headaches after doses of 1,20 , or $100 \mu \mathrm{g}$ histamine. All symptoms were rated by the subjects as mild in intensity.

In the second experiment, the administration of active desmopressin alone (treatment III) significantly depressed ( $P$ $<0.05)$ nasal blood flow response $(4 \pm 17 \%)$ compared with treatment I ( $75 \pm 25 \%)$, normal saline and desmopressin vehicle (Fig. 2). The intranasal administration of $20 \mu \mathrm{g}$ histamine before desmopressin (treatment IV) produced a nasal blood flow response $(103 \pm 24 \%)$ that was significantly higher $(P<0.02)$ than after desmopressin alone and comparable in magnitude to that produced by the combined vehicles (Fig. 2). Complaints related to treatments containing active histamine (treatments II and IV) were limited to headache in one subject (for both treatments) and nasal congestion in one subject (treatment IV).

Compared to vehicle (treatment I), urine osmolality was significantly increased $(P<0.05)$ for $6 \mathrm{~h}$ after either treatment with desmopressin alone (treatment III) or histamine and desmopressin (treatment IV) (Fig. 3). Urine osmolality was significantly higher $(P<0.03)$ during the initial 2 -h collection period after the combined administration of histamine and desmopressin (520 \pm 123 mosM) compared with desmopressin alone (333 \pm 75 mosM). Urine flow rate (Fig. 4) after desmopressin alone was significantly decreased $(P<0.05)$ for $6 \mathrm{~h}$ compared with saline and vehicle treatment, whereas the combination of histamine and desmopressin decreased $(P<0.05)$ urine flow rate for a total of $8 \mathrm{~h}$. Further, cumulative 24-h

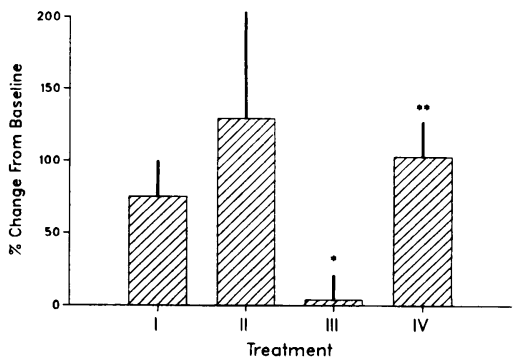

Figure 2. Nasal blood flow response (percent change from baseline). Effect of four different treatments on nasal mucosal blood flow, measured as maximal percent change from baseline, by laser doppler velocimetry techniques, $n=8$.

Treatments: I, saline followed by vehicle; II, histamine followed by vehicle; III, saline followed by desmopressin; IV, histamine followed by desmopressin. ** Greater than treatment III $(P<0.02)$; Less than treatment I $(P<0.05)$. Values expressed as mean \pm SEM.

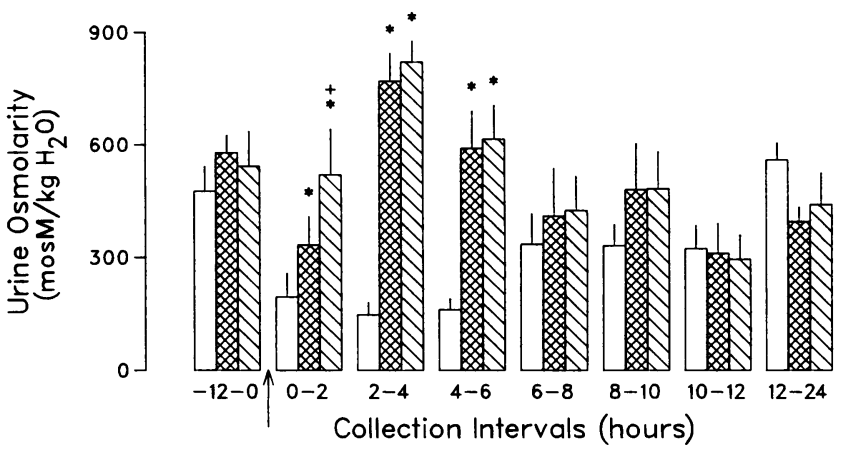

Figure 3. Urine osmolality response (milliosmolar per kilogram $\mathrm{H}_{2} \mathrm{O}$ ). Response to treatments: ( $\square$ ) saline followed by vehicle; $(\square)$ saline followed by desmopressin; ( $₫$ ) histamine followed by desmopressin. Arrow indicates time of oral water loading; mean \pm SEM values, $n=8$. * Greater than saline and vehicle $(P<0.05)$. + Greater than desmopressin alone $(P<0.03)$. Treatment with histamine alone not different than saline and vehicle (not shown).

urine volume was significantly decreased $(P<0.03)$ compared with saline and vehicle treatment $(4.1 \pm 0.64$ liter $)$ after histamine and desmopressin ( $3.0 \pm 0.52$ liter) but not with desmopressin alone. Histamine alone (treatment II, not shown in Figs. 3 or 4) had no effect on either urine osmolality or flow rate in these subjects.

The ability of histamine to acutely enhance the urine concentrating activity of desmopressin was also evidenced by the increases in urinary electrolyte and creatinine concentrations (Figs. 5-7). For the initial 2-h collection period, the effect of treatment with histamine and desmopressin was greater than with desmopressin alone, with respect to urine potassium ( $45 \pm 11$ vs. $28 \pm 7 \mathrm{meq} / \mathrm{liter}, P<0.03)$, sodium $(68 \pm 21$ vs. $36 \pm 8 \mathrm{meq} / \mathrm{liter}, P<0.03)$, and creatinine $(95 \pm 23$ vs. $60 \pm 13$ $\mathrm{mg} / \mathrm{dl}, P<0.03$ ) concentrations. During the subsequent two collection periods (2-4 and 4-6 h), both treatments induced equivalent increases in the concentration of urinary potassium, sodium, and creatinine, compared with saline and vehicle. Histamine alone had no effect on urinary electrolyte or creatinine concentrations.

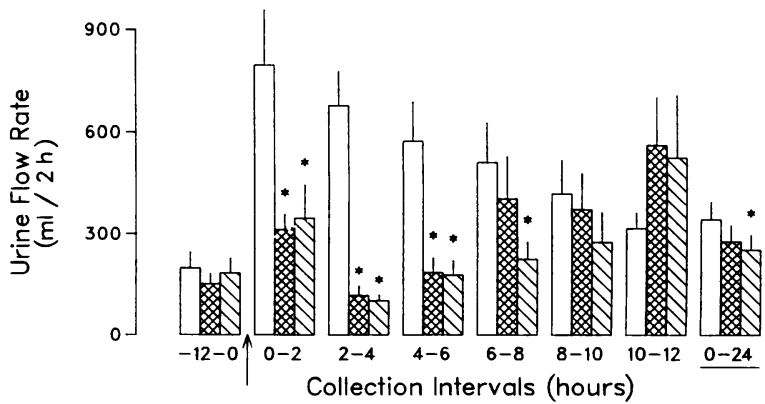

Figure 4. Urine flow rate response $(\mathrm{ml} / 2 \mathrm{~h})$. Response to treatments: (ㅁ) saline followed by vehicle; ( $($ ) saline followed by desmopressin; $(\mathbb{\nabla})$ histamine followed by desmopressin. Arrow indicates time of oral water loading, mean \pm SEM values, $n=8$. $*$ Greater than saline and vehicle, $P<0.05$; interval $(0-24 \mathrm{~h})$ at far right represents cumulative 24-h urine volume divided by 12 and is expressed as $\mathrm{ml} / 2 \mathrm{~h}$. Treatment with histamine alone not different than saline and vehicle (not shown). 


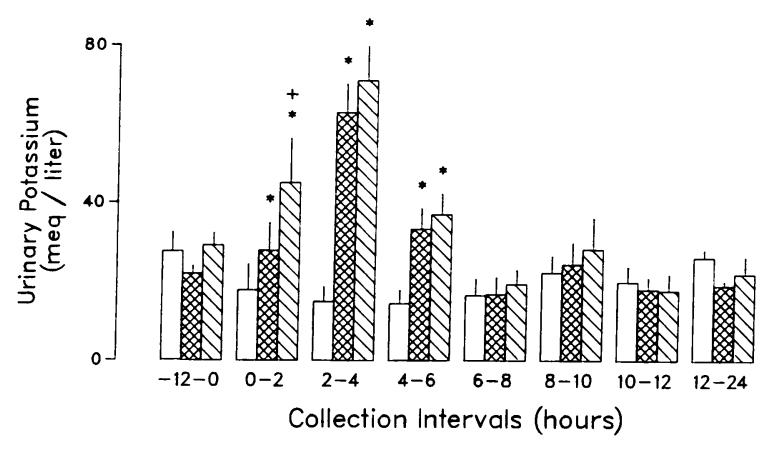

Figure 5. Urinary potassium concentration (milliequivalents per liter). Response to treatments: (ם) saline followed by vehicle; ( $\square$ ) saline followed by desmopressin; ( $₫$ ) histamine followed by desmopressin, mean \pm SEM values, $n=8$. Greater than saline and vehicle $(P$ $<0.05)$. $†$ Greater than desmopressin alone $(P<0.03)$. Treatment with histamine alone not different than saline and vehicle (not shown).

\section{Discussion}

Methodologies for evaluating nasal blood flow in humans include $133 \mathrm{Xe}$ washout (5), hydrogen clearance (19), thermal clearance (20), and laser doppler velocimetry techniques $(6$, 17). The first two methods involve invasive procedures and measure overall mean flow rather than local or superficial nasal blood flow. The thermal clearance technique, due to its design, is inherently sensitive to local environmental conditions of temperature and humidity and may be affected by any air movement in the nose. The laser doppler technique offers the advantages of continuous flow measurements, is noninvasive by design, and is capable of measuring superficial (mucosal) flow rates with appropriate equipment design. In addition, laser doppler flow measurements were shown not to vary when taken from the point of contact at the nasal mucosa and up to a distance of $3.5 \mathrm{~mm}$ from the mucosal surface (6). In the first experiment, we demonstrated a linear increase $(P<0.05)$ in the percent change in nasal blood flow, as measured by laser doppler velocimetry, in response to increasing doses of intranasal histamine. Previous work by Bende et al. (21) showed that nasal blood flow, as measured by $133 \mathrm{Xe}$ washout techniques, was increased by $71 \%$ after injection of $20 \mu \mathrm{g}$ histamine into the mucosa of the nasal inferior turbinate of normal sub-

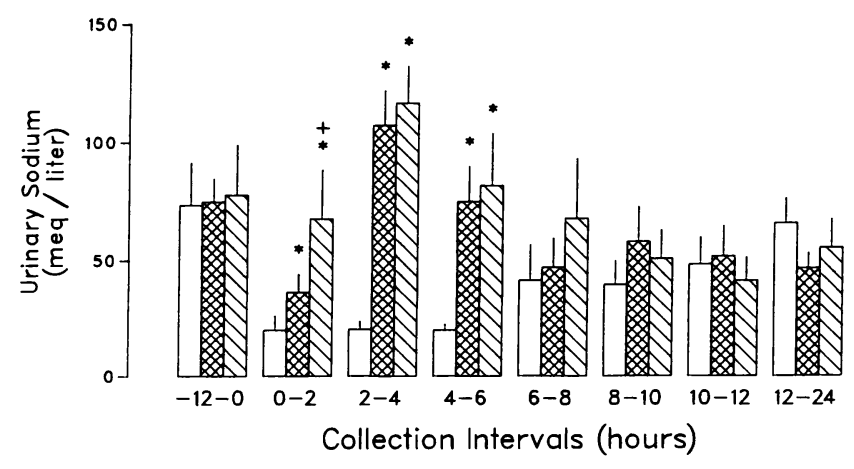

Figure 6. Urinary sodium concentration (milliequivalents per liter). Response to treatments: ( $\square$ ) saline followed by vehicle; $(\square)$ saline followed by desmopressin; $(\mathbb{Q})$ histamine followed by desmopressin, mean \pm SEM values, $n=8$. Greater than saline and vehicle $(P$ $<0.05)$. $†$ Greater than desmopressin alone $(P<0.03)$. Treatment with histamine alone not different than saline and vehicle (not shown).

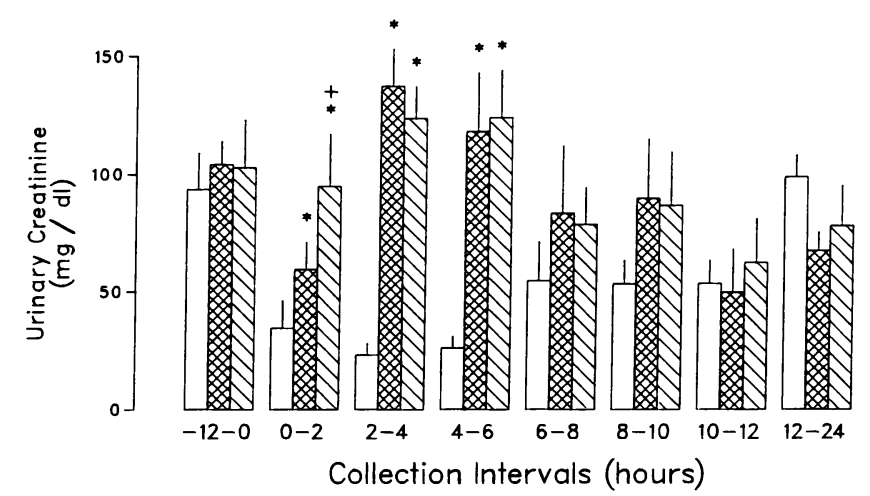

Figure 7. Urinary creatinine concentration (milligrams per deciliter). Response to treatments: () saline followed by vehicle; ( $\square$ ) saline followed by desmopressin; $(\mathbb{Q})$ histamine followed by desmopressin, mean \pm SEM values, $n=8$. Greater than saline and vehicle $(P$ $<0.05)$. $†$ Greater than desmopressin alone $(P<0.03)$. Treatment with histamine alone not different than saline and vehicle (not shown).

jects. Other exogenous vasoactive substances such as leukotriene $\mathrm{D}_{4}(2)$, and prostaglandin $\mathrm{E}_{1}(3)$, have also been shown to directly increase nasal blood flow in human subjects. Similarly in the cat, the beta adrenergic agonists isoproterenol and terbutaline produced vasodilation (22).

The mechanism by which histamine exerts its action on local nasal blood flow is unknown but may be related to capillary dilation mediated by both $\mathrm{H}_{1}$ and $\mathrm{H}_{2}$ receptors, both of which have been demonstrated in the blood vessels of the nasal mucosa (23). Stimulation of the vascular $\mathrm{H}_{1}$ receptor, with higher relative affinity for histamine, typically produces a more rapid, less sustained, vasodilatory response (24) similar to that observed in the current experiment. In the current experiments, the general lack of subjective complaints or visual evidence of mucosal edema would suggest that the response observed was not due to local irritant effects.

Our findings in the second experiment indicated that the prior intranasal application of $20 \mu \mathrm{g}$ histamine in normal subjects increased nasal blood flow, compared with desmopressin alone, and enhanced the antidiuretic activity of intranasal desmopressin. The effect of $10 \mu \mathrm{g}$ desmopressin in reducing urine flow rate was significantly prolonged by the addition of histamine, and its early effect in increasing urinary osmolality, and electrolyte and creatinine concentration was potentiated. Although not significantly different, urine osmolality values were consistently higher from 2 to $8 \mathrm{~h}$ after combined administration of histamine and desmopressin, compared with desmopressin treatment alone. That this effect was not more pronounced may be due to the experimental conditions used, in that the subjects had probably attained maximal urine concentrating capacity in their water-loaded state. Our decision to use the 20- $\mu$ g histamine dose in these experiments was based on the nasal blood flow response profile in the first experiment, and the previous report by Bende et al. (21), who found this dose to produce a significant increase in blood flow by 133 Xe washout techniques.

Although we were unable to measure actual desmopressin plasma levels, out findings are consistent with the hypothesis that histamine enhanced desmopressin activity by increasing its absorption through the nasal mucosa. Hammer and Vilhardt (25) have previously demonstrated a direct correlation between peak desmopressin levels and the duration of its anti- 
diuretic action. Other reports $(26,27)$ have implied that increasing doses of intranasal desmopressin primarily affected the duration of activity rather than the intensity of the antidiuretic effect.

The association of an increase in desmopressin activity with the demonstrated increase in nasal blood flow induced by histamine suggests that the transnasal absorption of the peptide is in part limited by blood flow. Alternatively, this action of histamine could be related to a direct effect on nasal mucosal permeability. Histamine in average doses of $10 \mathrm{mg}$ administered by oral nebulizer to seven healthy males produced a $65 \%$ increase in lung epithelial permeability to the low molecular weight tracer, ${ }^{99 \mathrm{~m}} \mathrm{Tc}$-diethylenetriamine penta-acetate (28). This rise in permeability was short lived ( 5 min or less) and was significantly attenuated by the $\mathrm{H}_{2}$ antagonist, ranitidine, but not by terfenadine, an $\mathrm{H}_{1}$ antagonist. Aerosolized histamine, administered in 3-mg doses, also increased guinea pig tracheal permeability to horse radish peroxidase, a protein of 40,000 mol wt (29). Electron microscopy demonstrated horse radish peroxidase reaction products in the intercellular spaces of the tracheal epithelium, without an attendant increase in intracellular vessicular transport, suggesting that the effect of histamine was to increase the leakiness of the intercellular tight junctions. The histamine doses used in the above references were 150 to 500 times higher than those in our desmopressin experiments, and thus the permeability increases observed may be the result of mucosal injury rather than a physiological increase in membrane transport (30). In the above studies, no consideration was given to the effect of these large doses of histamine on mucosal blood flow. It has also been shown that the intracellular tight junctions of nasal epithelium from patients with non-atopic chronic sinusitis or allergic rhinitis are relatively "leaky" to horseradish peroxidase, but that no intracellular protein uptake occurs (31). In the current study, we did not assess the effects of histamine on epithelial cell morphology; however, it is unlikely that the small histamine doses administered affected mucosal integrity. Additionally, the brief duration of the nasal blood flow response, observed after histamine administration in the current experiment, would suggest an $\mathrm{H}_{1}$ receptor-mediated mechanism rather than an $\mathrm{H}_{2}$ receptor-activated change in epithelial permeability. If in fact the absorption of intranasally administered peptide drugs can be enhanced by augmenting nasal blood flow, this approach may offer a means of improving the delivery and therapeutic efficacy of a number of higher molecular weight peptidic drugs including various hormonal agents.

In conclusion, nasal blood flow increased in a linear fashion with increasing doses of intranasal histamine. The administration of histamine immediately before desmopressin increased nasal blood flow response compared with desmopressin alone, and enhanced the antidiuretic action of this vasopressin analogue, presumably by increasing its absorption across the nasal membrane. In their ability to increase nasal blood flow, histamine, and similar physiological modifying agents, may promote the transnasal passage of drugs of limited mucosal permeability, such as biologically active peptides.

\section{Acknowledgments}

The authors wish to thank Dr. Carl Metzler for his assistance in the statistical interpretation of the results and Kathy Caswell for her preparation of the study diets. We also thank the personnel from the Bron- son Clinical Investigational Unit and the laboratory of the Clinical Research Laboratories of The Upjohn Co. for their assistance in the conduct of the study. The efforts of Dorothy A. Bergman and Pamala DeBoer in the preparation of the manuscript are appreciated.

\section{References}

1. Bende, M. 1983. Blood flow with ${ }^{133}$ Xe in human nasal mucosa in relationship to age, sex and body position. Acta Oto-laryngol. 69:175-179.

2. Bisgaard, H., P. Olsson, and M. Bende. 1984. Leukotriene $D_{4}$ increases nasal blood flow in human. Prostaglandins. 27:599-604.

3. Lung, M. A., and J. C. Wang. 1985. Nasal blood flow and airway resistance. Ann. Otol. Rhinol. Laryngol. 94:198-201.

4. Elway, S., and M. Toppozada. 1983. The effects of topical dinoprostone on the nasal vasculature. Arch. Oto-laryngol. 109:815-817.

5. Bende, M. 1983. Studies of blood flow in the human nasal mucosa. Eur. J. Respir. Dis. 64(Suppl. 128):400-402.

6. Olsson, P., M. Bende, and P. Ohlin. 1985. The laser doppler flowmeter for measuring microcirculation in human nasal mucosa. Acta Oto-laryngol. 99:133-139.

7. Bende, M., K. E. Andersson, C. J. Johansson, C. Sjogren, and G. Svensson. 1985. Vascular effects of phenylpropanolamine on human nasal mucosa. Rhinology. 23:43-48.

8. Bende, M., N. Lindqvist, and U. Pipkorn. 1983. Effect of a topical glucocorticoid, budesonide, on nasal mucosal blood flow as measured with ${ }^{133} \mathrm{Xe}$ wash-out technique. Allergy. 38:461-464.

9. Hussain, A. A., S. Hirai, and R. Bawarshi. 1979. Nasal absorption of propanolol in rats. J. Pharm. Sci. 68:1196.

10. Hussain, A. A., S. Hirai, and R. Bawarshi. 1981. Nasal absorption of natural contraceptive steroids in rats-progesterone absorption. J. Pharm. Sci. 70:466-467.

11. Sandow, J., and W. Petri. 1985. Intranasal administration of peptides, biological activity and therapeutic efficacy. Intransnasal Systemic Medications. Y. W. Chien, editor. Elsevier Science Publishers, Amsterdam. 183-199.

12. Andersson, K. E., and B. Arner. 1972. Effect of DDAVP, a synthetic analogue of vasopressin in patients with cranial diabetes insipidus. Acta Med. Scand. 192:21-27.

13. Rado, J. P., J. Marosi, and J. Fischer. 1977. Comparison of the antidiuretic effects of single intravenous and intranasal doses of DDAVP in diabetes insipidus. Pharmacology. 15:40-45.

14. Brooks, C. D., A. Nelson, R. Parzyck, and M. H. Maile. 1981. Protective effect of hydroxyzine and phenylpropanolamine in the challenged allergic nose. Ann. Allergy. 47:316-319.

15. Stern, M. D., D. L. Lappe, P. D. Bowen, J. E. Chimosky, G. A. Holloway, Jr., H. R. Keiser, and R. L. Bowman. 1977. Continuous measurement of tissue blood flow by laser-doppler spectroscopy. Am. J. Physiol. 232:H441-H448.

16. Bonner, R. F., T. R. Clem, P. D. Bowen, and R. L. Bowman. 1981. Laser-doppler continuous real-time monitor of pulsatile and mean blood flow in tissue microcirculation. In Scattering Techniques Applied to Supramolecular and Nonequilibrium Systems. S. H. Chen, B. Chu, and R. Nossal, editors. Plenum Publishing Corp., New York. 685-702.

17. Druce, H. M., R. F. Bonner, C. Patow, P. Choo, R. J. Summers, and M. A. Kaliner. 1984. Response of nasal blood flow to neurohormones as measured by laser-doppler velocimetry. J. Appl. Physiol. 57:1276-1283.

18. SAS Institute, Inc. 1985. SAS User's Guide: Statistics, Version 5 Edition. SAS Institute, Inc., Cary, NC. 431-506.

19. Tanimoto, H., M. Okuda, T. Yagi, and H. Ohtsuka. 1983. Measurement of blood flow of the nasal mucosa by the hydrogen clearance method. Rhinology. 21:59-65.

20. Nitzan, M., I. Brama, and Y. Mahler. 1985. Measurement of nasal mucosal blood flow by a thermal clearance method. IEEE (Inst. Electr. Electron. Eng.) Trans. Biomed. Eng. 32:1063-1066.

21. Bende, M., A. Elner, and P. Ohlin. 1984. The effect of provoked 
allergic reaction and histamine on nasal mucosal blood flow in humans. Acta Oto-laryngol. 97:99-104.

22. Malm, L. 1974. Beta-adrenergic receptors in the vessels of the cat nasal mucosa. Acta Oto-laryngol. 78:242-246.

23. Hiley, C. R., H. Wilson, and M. S. Yates. 1978. Identification of beta-adrenoreceptors and histamine receptors in the cat nasal vasculature, Acta Oto-laryngol. 85:444-448.

24. Douglas, W. D. 1985 . Histamine and 5-hydroxytryptamine (serotonin) and their antagonists. In The Pharmacological Basis of Therapeutics. A. G. Goodman, L. S. Goodman, T. W. Rall, and F. Murad, editors. Macmillan Publishing Co., New York. 605-638.

25. Hammer, M., and $H$. Vilhardt. 1985. Peroral treatment of diabetes insipidus with a polypeptide hormone analog, desmopressin. J. Pharmacol. Exp. Ther. 234:754-760.

26. Rado, J. P., J. Marosi, J. Fischer, J. Tako, and N. Kiss. 1975. Relationship between the dose of 1-deamino-8-D-arginine vasopressin
(DDAVP) and the antidiuretic response in man. Endokrinologie. 66:184-195.

27. Richardson, D. W., and A. G. Robinson. 1985. Desmopressin. Ann. Intern. Med. 103:228-239.

28. Braude, S., C. Coe, D. Royston, and P. J. Barnes. 1984. Histamine increases lung permeability by an $\mathrm{H}_{2}$ receptor mechanism. Lancet ii:372-374.

29. Boucher, R. C., V. Ranga, P. D. Pare, S. Inoue, L. A. Moroz, and J. C. Hogg. 1978. Effect of histamine and methacholine on guinea pig tracheal permeability to HRP. J. Appl. Physiol. 45:939-948.

30. Su, K. E., K. M. Campanale, and C. L. Gries. 1984. Nasal drug delivery system of a quaternary ammonium compound: clofilium tosylate. J. Pharm. Sci. 73:1251-1254.

31. Inagaki, M., Y. Sakakura, H. Itoh, K. Ukai, and Y. Miyoshi. 1985. Macromolecular permeability of the tight junction of the human nasal mucosa. Rhinology. 23:213-221. 